\title{
$\widehat{A}$ Madridge \\ madridge Journal of Nursing \\ Interconnecting Scientific World
}

Research Article

Open Access

\section{Prevalence of Substance Abuse among Omani Population in two Governorates in Sultanate of Oman}

\author{
Jokha Sulieman Mohammed Al Ghafri, Senaida Said Juma Al-Senaidi, and Jamaluddin Shaikh* \\ School of Pharmacy, College of Pharmacy and Nursing, University of Nizwa, Oman
}

\section{Article Info}

*Corresponding author:
Jamaluddin Shaikh
Associate Professor
School of Pharmacy
College of Pharmacy and Nursing
University of Nizwa
Oman
E-mail: jamaluddin@unizwa.edu.om

Received: December 15, 2020

Accepted: December 28, 2020

Published: December 30, 2020

Citation: Mohammed Al Ghafri JS, Juma Al-Senaidi SS, Shaikh J. Prevalence of Substance Abuse among Omani Population in two Governorates in Sultanate of Oman. Madridge J Nurs. 2020; 5(1): 167-172. doi: 10.18689/mjn-1000130

Copyright: (c) 2020 The Author(s). This work is licensed under a Creative Commons Attribution 4.0 International License, which permits unrestricted use, distribution, and reproduction in any medium, provided the original work is properly cited.

Published by Madridge Publishers

\begin{abstract}
Background: Substance abuse has a major impact on present-day life. It is one of the key issues in Sultanate of Oman as well. Its prevalence among youth is frightening. This problem is detrimental for individuals, and as a result, delivers destructive impression on families and community. However, the prevalence of substance abuse among Omani population is not well documented. The aim of this study is to evaluate the prevalence of substance abuse among Omani population in two Governorates in Sultanate of Oman.
\end{abstract}

Methodology: This study was carried out in Muscat and As-Sharqiyah South Governorates in Sultanate of Oman in the year 2015 among Omani population. To accomplish the purposes of the study, a self-administered questionnaire was distributed to both males and females. The questionnaire was constructed for the purpose of the study. It comprised of components to obtain demographic data and questions on substance abuse. Obtained data were analyzed to evaluate the response of the contributors. The collected data was interrelated with the demographic parameter of the abusers.

Results: A total of 1100 participants were participated in this study. Collected data in this study indicated that the prevalence of abusing substances were $18.9 \%$. Tobacco (40\%) and alcohol (39\%) are the most widespread substances among abusers. Among the gender distribution, 28.5\% male abused substances compared to $6.5 \%$ female abusers. A certain percentage of abusers also involved with sedative (8\%) and stimulants (11\%). The starting age of abusing substances was in the age group of $16-20$ (48\% in Muscat and 52\% in As-Sharqiyah South) with negligible data obtained as age of onset above 40 years. Majority of the users in this study addressed the family problem (53\% in Muscat and 23\% in As-Sharqiyah South) and bad relations (22\% in Muscat and $54 \%$ in As-Sharqiyah) as the main causes for substance addiction. Confirmed abusers also indicated that the neighboring environment was accountable for acquiring the substances.

Conclusion: This study was able to collect manageable data and represent a picture concerning substance abuse among Omani population. Data obtained from present study indicated that the tobacco and alcohol were the most abundant abused substances in Muscat and As-Sharqiyah South Governorates. The most common causes for such abuse are family problems and bad relations. This level of abusing may continue to their future life as we noticed half of them were unable to stop using substances.

Keywords: Substance abuse; Alcohol; Tobacco; Sedative; Stimulant. 


\section{Introduction}

Substance abuse is defined as troublesome ingestion of mood-changing substances that cause torment to mankind [1]. In other words, it refers to uncontrolled use of a substance in a way that is destructive to self, society, or both. This definition comprises both physical dependence and psychological dependence [2]. There are many contributing factors exist in the society to develop the habit of abusing substances. A person's psychological demands can be influenced by psychological factor. The person utilizes substances to self-medicate sentimental issues, such as unhappiness, loneliness, misery, despairs and depression [3].

Substance abuse is an escalating obstacle globally. Hundreds of thousands of people globally are abusing substances. One of the recent worldwide report estimated 269 million people had used substances at least once in the past year. The same report also indicated that the prevalence of substance abuse surged by over 12 per cent, from 2009 to 2018 [4]. It is a major health issue in the society today. It has a major impact on individuals, families, and communities. A huge number of adults frequently abuse alcohol, tobacco, heroin, cocaine, methamphetamine, prescription drugs, and other substances. People abuse substances for diverse and complex reasons, but it is obvious that the community pays substantial cost. The consequences of this abuse can be observed in the emergency departments of different hospitals [5].

It is revealed from the literature that drinking, smoking and illicit drug use are primary reasons of morbidity and mortality [6]. Overall, substance abuse related effects are paying to expensive social, mental, physical, and public health complications. These complications include but not limited to domestic violence, child abuse, automobile accidents, misconducts and murder [7-10]. Abuse substances including alcohol are a leading cause of escapable ailment and untimely death in many countries $[11,12]$. Alcohol-related calamities such as cirrhosis of liver, heart disease, neurological syndrome, and motor vehicle and other accident related mortalities. Tobacco, particularly cigarette smoking, accounts a huge number of fatalities worldwide. Nearly $90 \%$ of death due to lung cancer, about $80 \%$ of death due to chronic pulmonary disease, and about $20 \%$ death due to heart disease and stroke are related to cigarette smoking $[13,14]$.

Traditionally, native populations of the Gulf Countries and Arab Nations have not shown signs of substances abuse [15]. As Islamic religion has been practiced in its traditional form in these regions, may be the reason for such reflection [16]. However, smoking tobacco and its deviations, water pipe and Shisha, have been practiced since 17th century as a part of Arab custom [17]. Because of the increasing foreign population and the mounting tourism sector, the intake of substance has also amplified [18]. Not only alcohol and tobacco, the use of psychoactive constituents in this area has been intensified as well [15]. In spite of the social, cultural and religious unacceptability in Arab Nations, substance abuse is a frightening situation in this area [19]. It severely affects the wellbeing, economy, and society, and as a result, interferes with the development of the countries.

Oman, an Arabic Islamic country comprises of nine governorates, is located at the south-east border of Arabian Peninsula. As-Sharqiyah South Governorate is located at the south-east side of the country having a total population of little over 200,000. Muscat Governorate, the capital of Oman, on the other hand, is heavily populated area of Oman, having a total population of 1.5 million in metro area only.

A high percentage of the present-day Omani population is young [20]. World-wide studies have shown that youth are prone to be a high risk group for substances abuse in comparison to the rest age group $[21,22]$. Numerous literatures suggested that youth picking to test substances in their early phase of life are expected to face more complications in pleasing with their future lives $[23,24]$. Thus, detecting timely features among the population of young Omani, that marks them susceptible to abuse substances, is essential. There are, however, not many studies available on substance abuse in Sultanate of Oman. The current study aims to estimate the prevalence of substance abuse in Omani population in above mentioned governorates. This study may contribute assistance to the Government and the Ministry of Health to take benefits of the substance related interpretations to build a drug-free healthy environment.

\section{Materials and Methods}

This is a prospective study with the use of questionnaires for the evaluation of the prevalence of substance abuse among the Omani population in Muscat and As-Sharqiyah South Governorate, Sultanate of Oman. This study was carried out in the year 2015 by using self-administered questionnaires that included demographic parameters and questions about substance abuse. Demographic parameters of Omani public were also used in this study. The respondents' cultural parameters include age, gender, marital status, employment and education. Directly related questions regarding the start of substance use, the category of substances, fellow substance users, causes for abuse, drawbacks of substance use like losing friends, neglecting families, and medical complications concomitant with abuse, information about the distribution of the substances, role of the surrounding environment in substance abuse were all incorporated in the questionnaire.

A total number of 1100 Omani public, out of which 600 and 500 from Muscat and As-Sharqiyah South Governorates, respectively, were participated in the present study. The questionnaires were based on the following standardized international questionnaires used 
in previous similar studies [25]. These questionnaires are translated to Arabic (the local language) and validated. The validity was established by testing in a small population of subjects. All the acquired data were analyzed and demonstrated in histograms using Microsoft Excel programs.

\section{Results}

The present study was carried out in the Muscat and As-Sharqiyah South Governorates in Sultanate of Oman. Omani individual between the age of 18-60 years from both sexes who were willing to participate (consent was obtained from the participants) and those who could complete the questionnaire by themselves were included in this study.

The total numbers of respondents were 1100, out of which 600 from Muscat Governorate and 500 from AsSharqiya South Governorate. Among the participants, the percentage of male and female were $56 \%$ and $44 \%$, respectively. Regarding marital status, single and married participants were $59 \%$ and $41 \%$ respectively. About onehalf of the participants were high school graduates and higher degree holders.

In the present study, participants were asked if they had ever used drugs for non-medical purpose. The data confirmed that $18.9 \%$ of the participants reported affirmative response at least once in their life (Figure 1). Among the gender distribution, prevalence is more among male (28.5\%) than female (6.5\%). In relation to the prevalence between Governorates, Muscat Governorate (21.7\%) demonstrated more prevalence than As-Sharqiyah South Governorate (15.6\%). Male and female prevalence rate in Muscat Governorate were $30.8 \%$ and $5.9 \%$, respectively; whereas, the same in As-Sharqiyah South Governorate were $24.8 \%$ and $6.9 \%$, respectively (Figure 2).

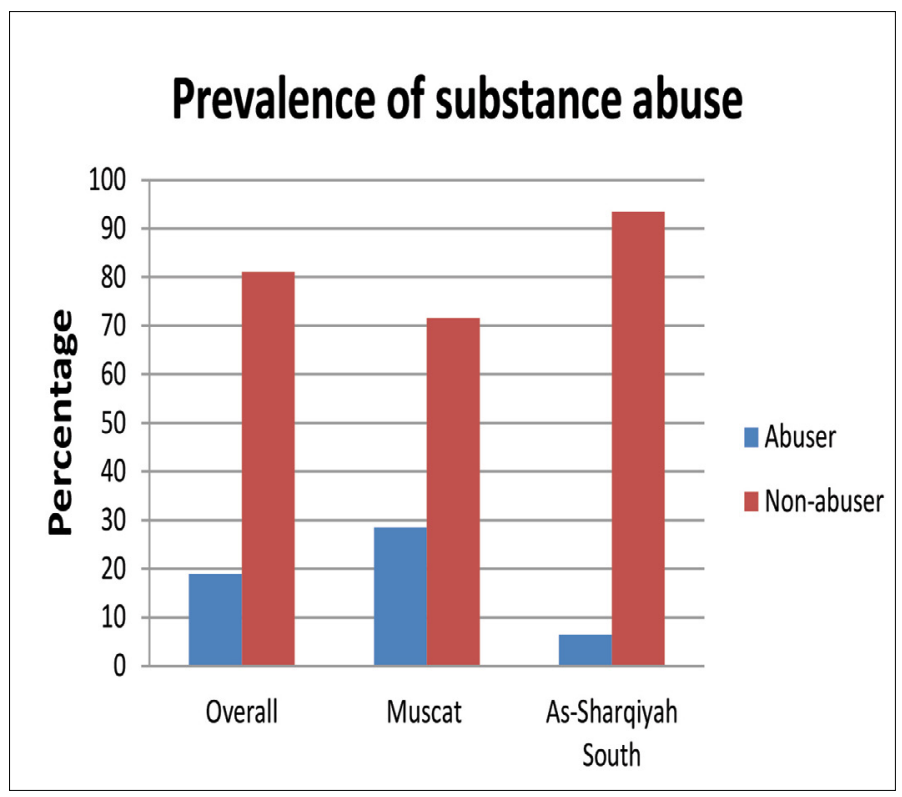

Figure 1. Prevalence of substance abuse between two Governorates.

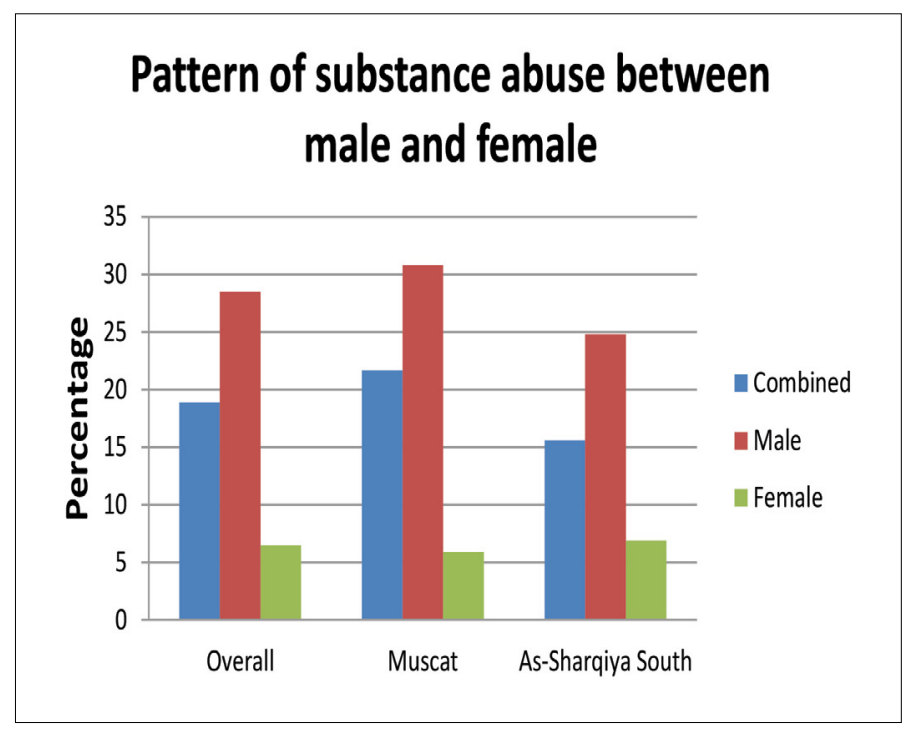

Figure 2. Pattern of substance abuse between male and female.

During assessment of frequency of substance abuse in Muscat Governorate, majority of the abusers specified their onset of substance abuse in between 16 and 20 years (48\%) followed by $21-25$ years (22\%). About one-half (52\%) of total abusers in As-Sharqiyah South Governorate was in the age group of $16-20$ years followed by $21-25$ years (24\%). With the increase of age the prevalence of substance abuse decreased, and eventually, a negligible percentage of people involved in substance abuse above 40 years of age (Figure 3).

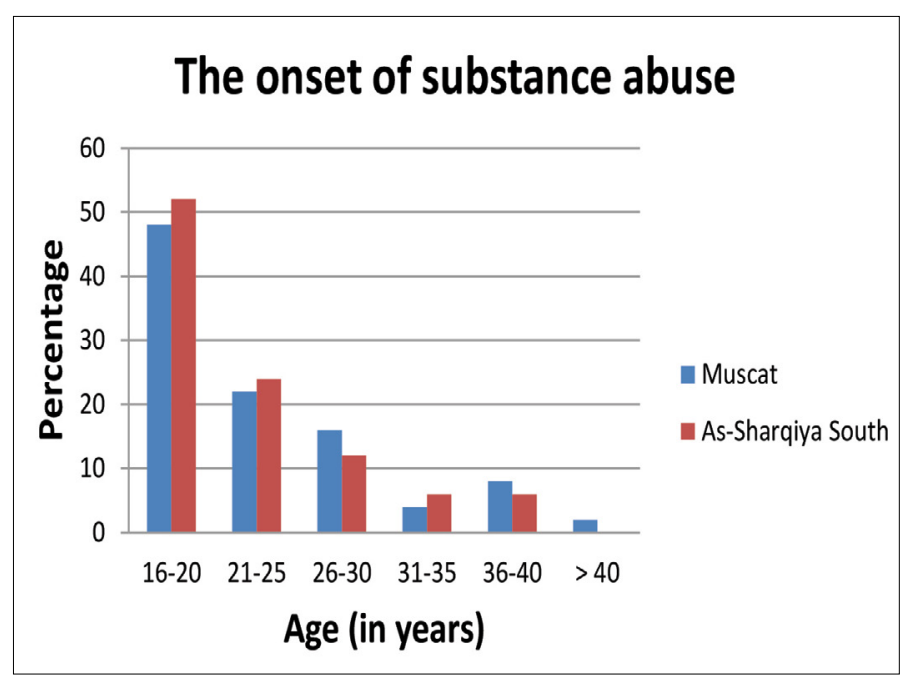

Figure 3. The age of onset of substance abuse.

In current study, tobacco (40\%) and alcohol (39\%) are most frequently used among abusers. Regarding the frequently used substances the majority of the abusers in Muscat Governorate confirmed the use of alcohol (46\%), tobacco $(27 \%)$ and sedative $(21 \%)$ as appeared in figure 4 . Regarding the segregation of sexes in the same governorate, the findings indicated that male abusers were mainly engaged with alcohol (57\%) and tobacco (35\%); whereas, female abusers were involved with alcohol (38\%), tobacco (30\%) and sedatives (24\%). Tobacco (40\%), on the other hand, is more prevalence in As-Sharqyiah South Governorates followed by stimulants (23\%) and sedatives 
(20\%). In the same governorate, male were mainly engaged with tobacco (53\%) and female were involved with stimulants (50\%) (Figure 4).
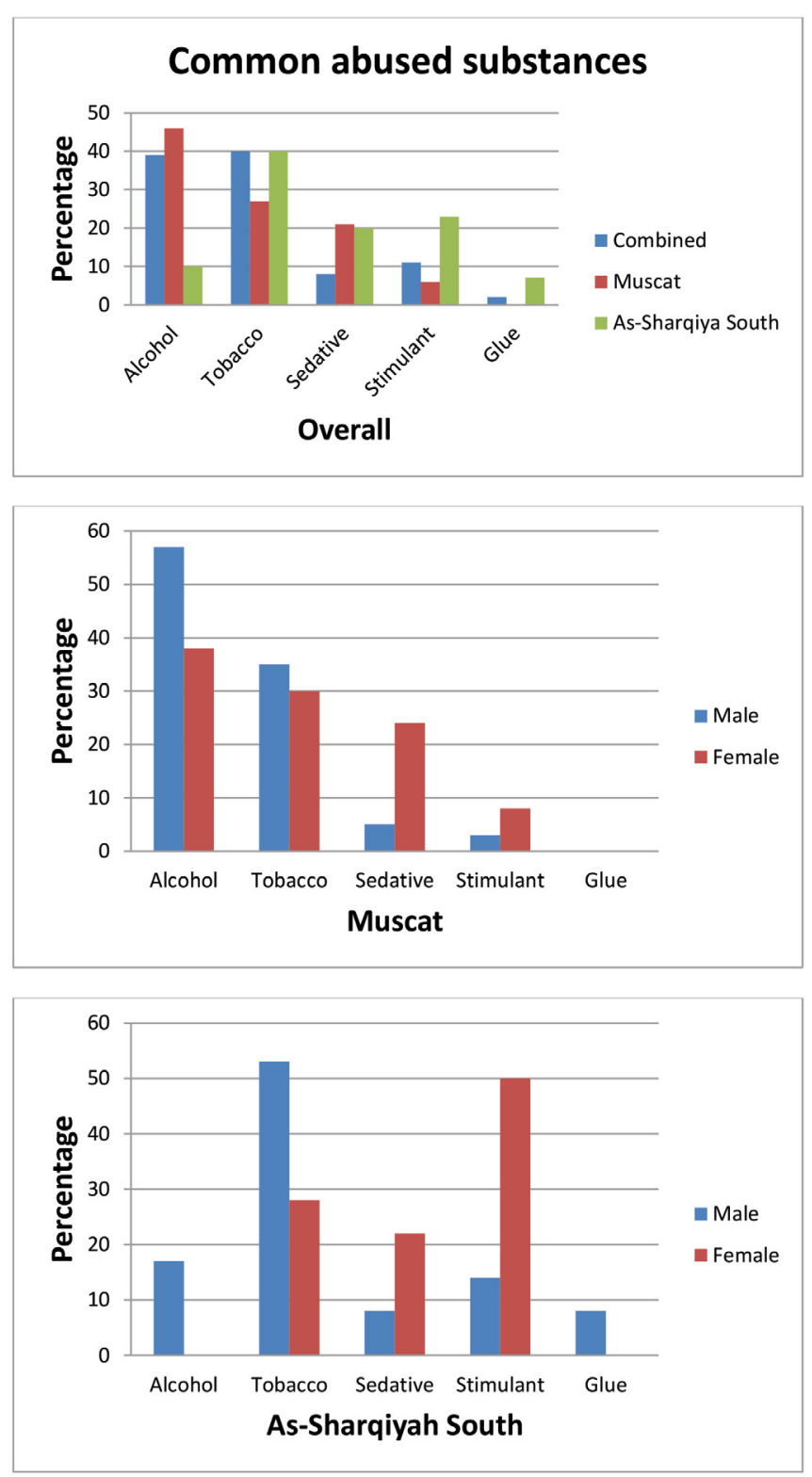

Figure 4. Common abused substances.

Concerning the belief of the abusers about possible motives of abusing substances, it was established that $53 \%$ of the abusers confirmed that family problems were the main causes for abusing substances in Muscat Governorate. Other significant suggestions for the basis of substance abuse in the same governorate were bad relation (22\%), followed by poverty (11\%). Bad relation (54\%), on the other hand, is more common cause of substance abuse in As-Sharqyiah South Governorates followed by family problem (23\%) as indicated in figure 5.

Abusers were questioned if the substance abuse engaged them in unlawful activities in order to acquire drugs. The results indicated that one-fourth (25\%) of them reported the affirmative response. About two-fifth of abusers were not feeling any guilty because of abusing substances. Available data also indicated that half of them were unable to discontinue using substances whenever they want. Results in the present study also pointed out that $52 \%$ and $28 \%$ abusers from Muscat and As-Sharqiyah Governorates, respectively, knew the distribution procedure of substances. As per abuser environment is influencing people to engaged with substances.

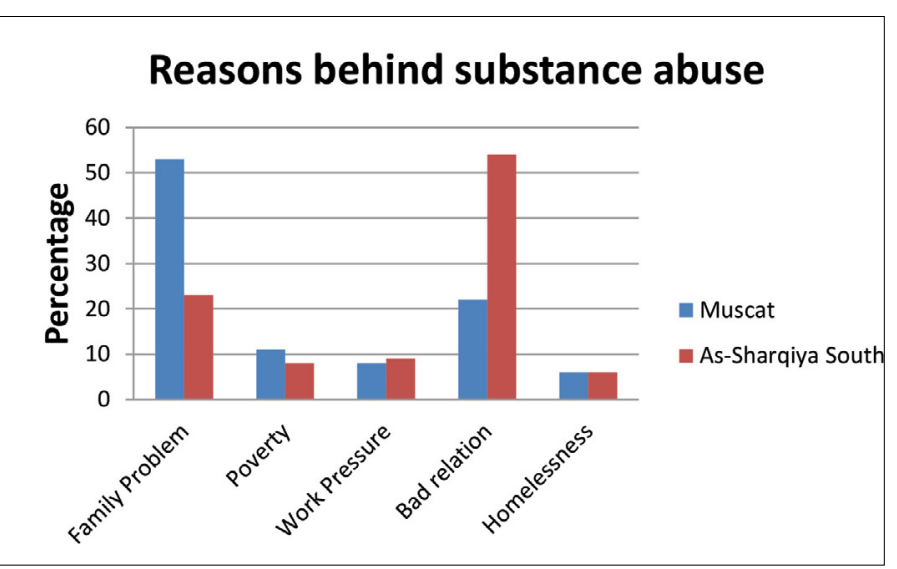

Figure 5. Reasons behind substance abuse.

\section{Discussion}

Lifestyles can influence people's life, their education, wellbeing, economy and social designs. Abusing substance is reflected as one of the problem of the humanity especially when the abusers are in younger age. Thus, avoidance and timely recognition and interference are important to fight against substance abuse [26]. This ailment is an avoidable and curable health consequence via wide range of interventions. The strategies can be fixed for treatment based on indication and scientific parameter [27]. Abundant statistics, however, is not available on substance use in Sultanate of Oman. The Muscat Governorate is one of the nine administrative regions and capital of Sultanate of Oman; whereas, As-Sharqiyah South is composed of many small towns. Sultanate of Oman as a whole is considered a religious country with firm adherence of Islamic ethics and the substance abuse, particularly alcohol is prohibited. In fact, abusing substance is a social dishonor and intolerable in the Omani culture. As number of abuse is not conveyed to the consideration of Government institutions on time, strategies against this social calamity is not planned properly.

The trend for substance abuse among Omani population survey indicated that about twenty percent of the respondents were involved with substance abuse. The male abusers outnumbered female abuser in this study, as shown in the data from gender distribution. This is in line with a similar finding from a previous study [28].

Abusing substance is a complicated and multidirectional issue. As per modern global setup, the age of onset of drinking alcohol is decreasing and youth generations are starting drug as early as adolescent age. Abuse among younger population is rising due to internet and globalization. In our study, the most of the abusers are young, started abusing substances between 16 to 20 years 
of age. This observation is similar to previously reported study that confirmed the age of substance abuse was started during adolescents and early adulthood [29]. As the age increases people rarely take the initiative to start abusing substances [30].

Overall, consumption of alcohol is less in Arab countries due to religious belief. However, it is not completely abundant in this region. In this study, a considerable percentage of abusers appeared to consume alcohol. Prevalence is more in Muscat Governorate because of its cosmopolitan characteristics and easy availability of alcohol. As As-Sharqiyah South is consists of small towns and accessibility of alcohol is not so easy, drug abusers are more lenient to tobacco. In As-Sharqiyah South Governorate, less prevalence of alcohol may be due to inadequate supply. Traditionally, prevalence of alcohol among female are less than males [31] which reflected in our findings. Among the many substances, a sizeable percentage of people use tobacco in both the Governorates. Our studies in line with the prevalence of tobacco use in Saudi Arabia and US [32,33].

Majority of the female in our study in As-Sharqiyah South Governorates are involved in stimulant, which is in accordance with a previous study [34]. However, Canadian and US studies indicated a less use of stimulant than our observations $[35,36]$. This difference may be because of the easy availability of khat, which is a popular herbal stimulant use in Arab world [37]. As it is one of the main contributors in the stimulant category, prevalent use of khat in these regions revealed in the present study. Sedatives also frequently abused in this study. A widespread use of sedative among young population has been reported in Arabian countries [38].

Majority of the abusers from Muscat Governorate pointed out that family problems are the main cause for substance abuse. Family has a key impact on the habit of its members. It is important to mention that family sometime influences on the practice of substance abuse. By the by, relationships among family members and role model characteristics of parents are important as well [39]. Few family factors may take leading role for trapping to the substances. These factors may include, but not limited to, improper family management, indiscipline and pessimistic communication techniques [40].

Data from As-Sharqiyah South Governorate demonstrated that bad relations are the main cause of substance abuse which is in line with previously published data $[41,42]$. Good relation with family, friends, and society is an important parameter for healthiness of life. If this relationship is in torment, people can suffer with depression and mental illness which can lead a person towards drug addiction.

\section{Conclusions}

This study was conducted among the Omani population, both males and females, in Muscat and AsSharqiyah South Governorates in Sultanate of Oman. The most abuse substances were tobacco and alcohol. The obtained data was helpful in relating and interpreting an idea about the prevalence of substance abuse. In connection with substance abuse, prevalence among males was more than females and most of abusers started abusing substances at an early age (in between 16-20 years). Concerning the substances, males were more lenient to abusing tobacco and alcohol; whereas, females were prone to abuse stimulants. Family problem and bad relation were among the origins that inspire them to abuse substances. This study also indicated that about two-fifth of the abusers did not bother about their habit and about half of the abusers were aware about the distribution procedure of substances.

\section{Acknowledgment}

We would like to express our thanks and gratitude to the University of Nizwa and the College of Pharmacy and Nursing for giving this opportunity to conduct this research via the provision of the academic programs.

\section{Declaration of Conflicts of Interest}

The authors declared no conflicts of interest with respect to the authorship and/or publication of this.

\section{References}

1. Zou Z, Wang H, Uquillas FD, Wang X, Ding J, Chen H. Definition of Substance and Non-substance Addiction. Adv Exp Med Biol. 2017; 1010: 21-41. doi: 10.1007/978-981-10-5562-1_2

2. Dew B, Elifson K, Dozier M. Social and environmental factors and their influence on drug use vulnerability and resiliency in rural populations. J Rural Health. 2007; 23: 16-21. doi: 10.1111/j.1748-0361.2007.00119.x

3. Harris KM, Edlund MJ. Self-medication of mental health problems: New evidence from a national survey. Health Serv Res. 2005; 40(1): 117-134. doi: 10.1111/j.1475-6773.2005.00345.x

4. UNODC. World Drug Report 2020. United Nations Office on Drugs and Crime. 2020.

5. Nutt D, King LA, Saulsbury W, Blakemore C. Development of a rational scale to assess the harm of drugs of potential misuse. Lancet. 2007; 369(9566): 1047-1053. doi: 10.1016/S0140-6736(07)60464-4

6. Chassin L, Pitts SC, Prost J. Binge drinking trajectories from adolescence to emerging adulthood in a high-risk sample: predictors and substance abuse outcomes. J Consult Clin Psychol. 2002; 70(1): 67-78. doi: 10.1037/0022-006X.70.1.67

7. Zilberman ML, Blume SB. Domestic violence, alcohol and substance abuse. Brazilian Journal of Psychiatry. 2005; 27:s51-s55. doi: 10.1590/ S1516-44462005000600004

8. Derakhshanfar H, Meibodi MK, Kariman H, Arhamidolatabadi A, Safari S Substance abuse among drivers of motor vehicle collisions. Trauma Mon. 2012; 17(1): 236-238. doi: 10.5812/traumamon.4182

9. Goldberg AE, Blaauw E. Parental substance use disorder and child abuse: risk factors for child maltreatment? Psychiatr Psychol Law. 2019; 26(6): 959-969. doi: 10.1080/13218719.2019.1664277

10. Eriksson L, Bryant S, McPhedran S, Mazerolle P, Wortley R. Alcohol and drug problems among Australian homicide offenders. Addiction. 2020. doi: 10.1111/add.15169 
11. Rehm J, Taylor B, Room R. Global burden of disease from alcohol, illicit drugs and tobacco. Drug Alcohol Rev. 2006; 25(6): 503-513. doi: 10.1080/09595230600944453

12. Probst $\mathrm{C}$, Parry $\mathrm{CDH}$, Wittchen $\mathrm{H}-\mathrm{U}$, Rehm J. The socioeconomic profile of alcohol-attributable mortality in South Africa: a modelling study. BMC Med. 2018; 16(1): 97. doi: 10.1186/s12916-018-1080-0

13. Shield KD, Parry C, Rehm J. Chronic diseases and conditions related to alcohol use. Alcohol Res. 2014; 35(2): 155-171.

14. Samet JM. Tobacco smoking: the leading cause of preventable disease worldwide. Thorac Surg Clin. 2013; 23(2): 103-112. doi: 10.1016/j.thorsurg.2013.01.009

15. AlMarri TSK, Oei TPS. Alcohol and substance use in the Arabian Gulf region: A review. Int J Psychol. 2009; 44(3): 222-233. doi: $10.1080 / 00207590801888752$

16. Zaidan ZAJ, Dorvlo ASS, Viernes N, Al-Suleimani A, Al-Adawi S. Hazardous and harmful alcohol consumption among non-psychotic psychiatric clinic attendees in Oman. Int J Ment Health Addict. 2007; 5: 3-15. doi: 10.1007/s11469-006-9046-4

17. Quadri MF, Saleh SM, Alsanosy R, et al. Effectiveness of an intervention program on knowledge of oral cancer among the youth of Jazan, Saudi Arabia. Asian Pac J Cancer Prev. 2014; 15(5): 1913-1918. doi: 10.7314/APJCP.2014.15.5.1913

18. Al-Adawi S. Substance abuse in the Gulf cooperation Council States. In: Mamtani R, Lowenfels AB (eds). Critical Issues in Healthcare Policy and Politics in the Gulf Cooperation Council States. Washington; Georgetown University Press. 2017: 113-136.

19. World Health Organization. World Health Organization Regional Office for the Eastern Mediterranean Questionnaire for Regional Situation Analysis on Drug Abuse. Cairo, WHO, Regional Office for the Eastern Mediterranean 2003.

20. World Population Review. Oman Population 2018. 2018.

21. Goings TC, Hidalgo ST, McGovern PP. Racial/Ethnic Differences in Cigarette Use Trends in the United States among Multiracial and Other Youth, 1994-2008. J Drug Issues. 2018; 48(1): 90-105. doi: $10.1177 / 0022042617731338$

22. Duell N, Steinberg L, Icenogle $G$, et al. Age patterns in risk taking across the world. J Youth Adolesc. 2018; 47(5): 1052-1072. doi: 10.1007/ s10964-017-0752-y

23. Cheung YW, Cheung NW. A longitudinal survey of psychoactive drug abusers in Hong Kong. In: Psychoactive Drug Abuse in Hong Kong. Springer, Singapore. 2018: 15-32.

24. Lander L, Howsare J, Byrne M. The impact of substance use disorders on families and children: from theory to practice. Soc Work Public Health. 2013; 28(3-4): 194-205. doi: 10.1080/19371918.2013.759005

25. NIDA. Diagnosis and Treatment of Drug Abuse in Family Practice American Family Physician Monograph. National Institute on Drug Abuse. 2003.

26. Siddiqui AF, Salim AM. Awareness of substance use and its associated factors in young Saudi students. J Med Allied Sci. 2016; 6(2): 61-67. doi: 10.5455/jmas. 217010

27. Badr LK, Taha A, Dee V. Substance abuse in Middle Eastern adolescents living in two different countries: Spiritual, cultural, family and personal factors. J Relig Health. 2014; 53(4): 1060-1074. doi: 10.1007/ s10943-013-9694-1
28. Van Etten ML, Anthony JC. Male-female differences in transitions from first drug opportunity to first use: searching for subgroup variation by age, race, region, and urban status. I Womens Health Gend Based Med. 2001; 10(8): 797-804. doi: 10.1089/15246090152636550

29. Arute JE, Oyita GI, Eniojukan JF. Substance Abuse among Adolescents: 2. Prevalence and Patterns of Cigarette smoking among senior secondary school students in Abraka, Delta State, Nigeria. IOSR Journal of Pharmacy. 2015; 5(1): 40-47.

30. Strashny A. Age of substance use initiation among treatment admissions aged 18 to 30. In: The CBHSQ Report. Substance Abuse and Mental Health Services Administration (US). 2014.

31. Centers for Disease Control (CDC). Alcohol and other drug use among high school students--United States, 1990. MMWR Morb Mortal Wkly Rep. 1991; 40(45): 776-777, 783-784.

32. Bassiony M. Substance use disorders in Saudi Arabia: review article. $J$ Subst Use. 2013; 18(6): 450-466. doi: 10.3109/14659891.2011.606349

33. Arrazola RA, Singh T, Corey CG, et al. Tobacco use among middle and high school students - United States, 2011-2014. MMWR Morb Mortal Wkly Rep. 2015; 64(14): 381-385.

34. Eegunranti BA, Fatoye FO, Morakinyo O. Stimulant use among secondary school students in Osogbo, Nigeria. Niger Postgrad Med J. 2009; 16(3): 218-223.

35. Johnson LD, O'Malley PM, Bachman JG. Secondary school students. Vol 1 of National survey results on drug use from the Monitoring the Future Study, 1975-1998. Washington: US Department of Health and Human Services. 1999.

36. Poulin C, Elliott D. Alcohol, tobacco and cannabis use among Nova Scotia adolescents: implications for prevention and harm reduction. CMAJ. 1997; 156(10): 1387-1393.

37. Ageely HM. Prevalence of Khat chewing in college and secondary (high) school students of Jazan region, Saudi Arabia. Harm Reduction Journal. 2009; 6(1): 11. doi: 10.1186/1477-7517-6-11

38. Al-Sayed AA, Al-Rashoudi AH, Al-Eisa AA, et al. Sedative drug use among King Saud University medical students: A cross-sectional sampling study. Depression Research and Treatment. 2014. doi: $10.1155 / 2014 / 378738$

39. World Health Organization. Atlas on substance use (2010): resources for the prevention and treatment of substance use disorders. 2010.

40. Fekadu A, Alem A, Hanlon C. Alcohol and drug abuse in Ethiopia: past, present and future. Afr J Drug Alcohol Stud. 2007; 6(1): 40-53.

41. Bohnert AS, German $D$, Knowlton AR, Latkin CA. Friendship networks of inner-city adults: A latent class analysis and multi-level regression of supporter types and the association of supporter latent class membership with supporter and recipient drug use. Drug Alcohol Depend. 2010; 107(2-3): 134-140. doi: 10.1016/j.drugalcdep.2009.09.012

42. Farris $C A$, Fenaughty $A M$. Social isolation and domestic violence among female drug users. Am J Drug Alcohol Abuse. 2002; 28(2): 339351. doi: $10.1081 /$ ada-120002977 